\title{
Periprocedural Management during Placement of Flow Diverters in Intracranial Aneurysms: A Clinical Report and Review of Literature
}

\author{
Rajeeb K. Mishra $\quad$ Charu Mahajan² Indu Kapoor ${ }^{2}$ \\ ${ }^{1}$ Department of Neuroanaesthesiology and Neurocritical Care, \\ National Institute of Mental Health and Neurosciences, Bengaluru, \\ Karnataka, India \\ 2Department of Neuroanaesthesiology and Critical Care, All India \\ Institute of Medical Sciences, New Delhi, India
}

Hemanshu Prabhakar²

J Neuroanaesthesiol Crit Care:2021;8:52-56

\author{
Address for correspondence Charu Mahajan, MD, DM, Department \\ of Neuroanaesthesiology and Critical Care, Neurosciences Centre, \\ All India Institute of Medical Sciences, New Delhi 110029, India \\ (e-mail: charushrikul@gmail.com).
}

\begin{abstract}
Keywords

- flow diverter

- anesthetic management

- intracranial aneurysms

Background Placement of flow diverter (FD) is an endovascular technique where the flow to the aneurysm is directed away from the aneurysmal sac using a stent in the parent vessel. In this clinical report, the authors share their institutional experience pertaining to clinical course of patients with intracranial aneurysm requiring placement of FD.

Methods After approval from institute ethics committee (IEC), the authors retrospectively studied all patients who underwent placement of FD for intracranial aneurysms from January 2014 to December 2017. Data regarding patient demographics, presenting complaints, aneurysm details, anesthesia technique, and intra- and postprocedural complications were noted. Duration of hospital stay, neurological outcome as measured by Glasgow outcome scale (GOS) at discharge and at 6 months was noted. Data are presented as median (range) or number (\%).

Results Over a period of 3 years, 22 patients underwent FD placement. Two patients had subarachnoid hemorrhage (SAH) at the time of presentation, and the rest had unruptured aneurysms. All patients received general anesthesia (GA) for the procedure, and intravenous propofol was used for induction of anesthesia. Majority of the patients received sevoflurane and nitrous oxide combination for maintenance of anesthesia (20/22 [91\%]). Five patients were not extubated at the end of the procedure. The most common indication for mechanical ventilation was delayed reversal because of hypothermia. At 6 months of follow-up, GOS was 5 in 18 patients. None of the patients developed any delayed complications related to FD and were neurologically intact.

Conclusions The use of FD for the treatment of aneurysms is a safe option. GA was used for carrying out procedure in all patients. The neurological outcome was good in all patients who were followed at 6 months.
\end{abstract}

\section{Introduction}

Flow diverter (FD) placement is an endovascular technique where the flow to the aneurysm is directed away from the aneurysmal sac by placing a stent in the parent vessel (-Fig. 1). It also causes neo-intimal proliferation that completely occludes the inflow to the aneurysm. ${ }^{1,2}$ The indications for this device placement are complex aneurysm configurations, giant aneurysms, fusiform, or wide-necked aneurysms, where both conventional coiling and clipping are
Published online August 4, 2020
DOI https://doi.org/ $10.1055 / \mathrm{s}-0039-1693501$ ISSN 2348-0548.
(C2020. Indian Society of Neuroanaesthesiology and Critical Care. This is an open access article published by Thieme under the terms of the Creative Commons Attribution-NonDerivative-NonCommercial-License, permitting copying and reproduction so long as the original work is given appropriate credit. Contents may not be used for commercial purposes, or adapted, remixed, transformed or built upon. (https://creativecommons.org/licenses/by-nc-nd/4.0/).

Thieme Medical and Scientific Publishers Pvt. Ltd. A-12, 2nd Floor, Sector 2, Noida-201301 UP, India 


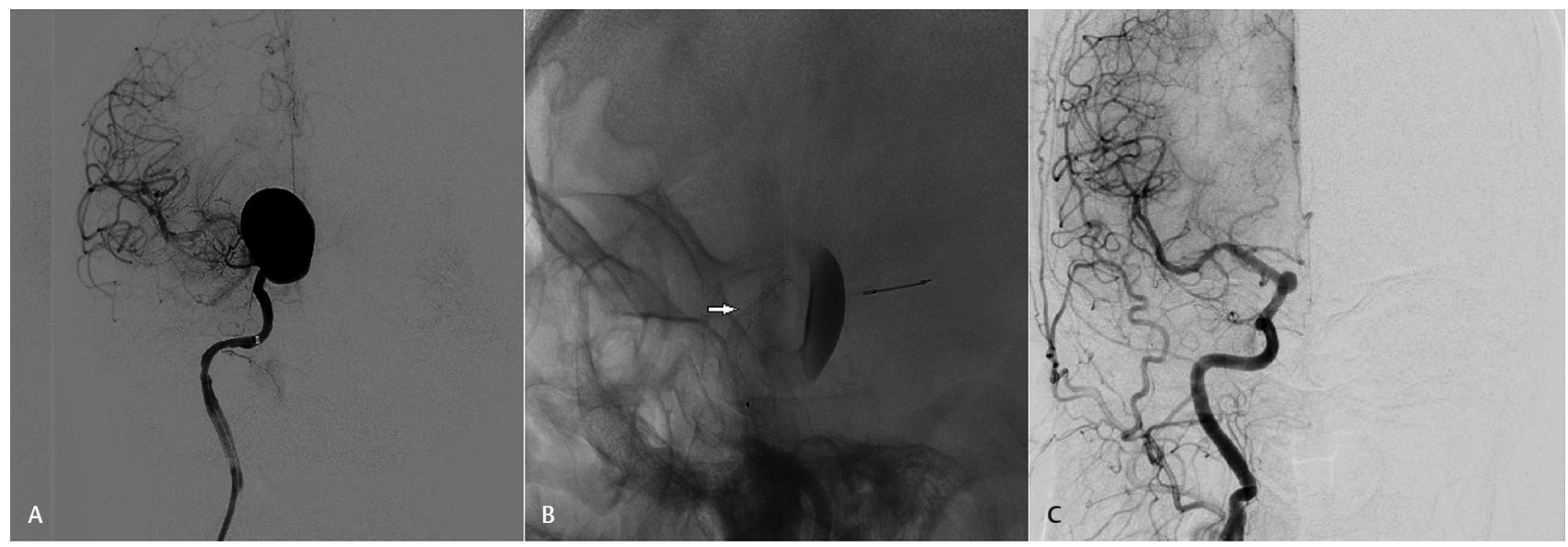

Fig. 1 Digital subtraction angiography (DSA) images showing different stages of treatment. (A) Pretreatment giant right-side ophthalmic segment internal carotid artery aneurysm. Note the filling of aneurysmal sac. (B) Flow diverter in situ (white arrow) and reduced filling of sac. (C) Follow-up image showing reduced sac size.

difficult to perform. Previous literature has demonstrated that the use of the FD has high rates of aneurysm occlusion with relatively low complication rates. ${ }^{3,4}$ Flow diversion leads to reduced hemodynamic stress velocity within the sac of the aneurysm, which results in a reduced risk of re-rupture and better long-term occlusion. The anesthetic concerns and the associated complications related to their placement have not been studied earlier. In this case series, the authors share their institutional experience pertaining to the periprocedural care and the clinical course of patients with intracranial aneurysm requiring placement of FD.

\section{Methods}

After approval from institute ethics committee (IEC), the authors included all patients who underwent endovascular therapy with placement of FD for intracranial aneurysms from January 2014 to December 2017. Data regarding patient demographics, presenting complaints, ruptured or unruptured aneurysm, its size, location, details of anesthesia technique, and intra- and postprocedural complications were noted. Duration of hospital stay, follow-up imaging data, and neurological outcome (as assessed by Glasgow outcome scale [GOS]) at discharge and at 6 months were also noted. Data are presented as median (range) or number (\%).

\section{Results}

Over a period of 3 years, 22 patients having aneurysms at different sites underwent FD placement procedures. The demographics, presenting complaints, and comorbidities are listed in (-Table 1). All had unruptured aneurysms except two patients, who had recent history (3 and 7 days) of subarachnoid hemorrhage (SAH) at the time of presentation. All the aneurysms were located in the anterior circulation (-Table 1). During procedure, all patients received intravenous propofol as an agent for anesthesia induction. The standard monitoring included electrocardiography, noninvasive blood pressure monitoring, pulse oximetry, end-tidal carbon dioxide, skin temperature, and urine output in all patients.
Table 1 Demographics and clinical characteristics of patients

\begin{tabular}{|c|c|c|}
\hline \multicolumn{2}{|l|}{ Age (y) } & $50(30-66)$ \\
\hline \multicolumn{2}{|l|}{$\operatorname{Sex}(M: F)$} & $3: 18$ \\
\hline \multicolumn{2}{|l|}{ Weight $(\mathrm{kg})$} & $60(48-80)$ \\
\hline \multicolumn{2}{|l|}{ ASA I/II/III } & $12 / 8 / 2$ \\
\hline \multicolumn{2}{|l|}{$\begin{array}{l}\text { Comorbidities } \\
\text { - Hypertension } \\
\text { - Diabetes }\end{array}$} & $\begin{array}{l}8(36.3) \\
1(4.5)\end{array}$ \\
\hline \multirow[t]{4}{*}{ Presentation } & Headache & $17(77.2)$ \\
\hline & Vision impairment & $7(31.8)$ \\
\hline & Diplopia & $4(18.1)$ \\
\hline & Ptosis & $2(9.0)$ \\
\hline \multicolumn{2}{|l|}{ Recent SAH } & $2(9.0)$ \\
\hline \multirow[t]{4}{*}{ Aneurysm size } & $<7 \mathrm{~mm}$ & $6(27.2)$ \\
\hline & $7-12 \mathrm{~mm}$ & $4(18.1)$ \\
\hline & $13-24 \mathrm{~mm}$ & $6(27.2)$ \\
\hline & $\geq 25 \mathrm{~mm}$ & $6(27.2)$ \\
\hline \multirow[t]{5}{*}{ Location } & Cavernous ICA & 9 (40.9) \\
\hline & Clinoidal ICA & $2(9.0)$ \\
\hline & Ophthalmic ICA & $7(31.8)$ \\
\hline & Communicating ICA & $1(4.5)$ \\
\hline & Superior hypophyseal & $3(13.6)$ \\
\hline
\end{tabular}

Abbreviations: ASA, American Society of Anesthesiologists; F, female; ICA, internal carotid artery; $\mathrm{M}$, male; $\mathrm{SAH}$, subarachnoid hemorrhage. Note: Numbers expressed as median (range), number (\%).

In addition, arterial catheterization was performed in all patients for carrying out beat-to-beat blood pressure monitoring. Most patients received a combination of sevoflurane and nitrous oxide for maintenance of anesthesia (20/22 [91\%]). All patients received intravenous heparin during the procedure to maintain an activated clotting time of 2 to 2.5 times the baseline value. The duration of the whole procedure was 210 (120-325) minutes. One patient developed intraprocedural FD thrombosis that was promptly taken care of by intra-arterial abciximab. Postprocedural systolic blood 
pressure was kept in the range of 140 to $150 \mathrm{~mm} \mathrm{Hg}$. Five out of 22 patients were not tracheally extubated at the end of the procedure. The most common indication for mechanical ventilation was delayed reversal due to hypothermia (4/5 [80\%]). Postoperatively, two patients developed motor deficits that improved subsequently. On postoperative day 2, one patient died of large parietal hematoma and increased intracranial pressure. The median duration of hospital stay was 7 (5-20) days. At discharge, the mean GOS was 4 in all patients, except one who had a GOS of 1 (died). Follow-up digital subtraction angiography (DSA) showed small residual aneurysms in 4 of 21 patients. All patients who were followed up at 6 months $(18 / 21)$ had a GOS of 5 . None of the patients developed any delayed complications related to FD and were neurologically intact.

\section{Discussion}

In this case series, the authors collected data regarding the periprocedural care and the clinical course of patients with intracranial aneurysm requiring placement of FD. The most common presenting symptom was headache due to mass effect of unruptured aneurysm. One patient had a history of SAH, 3 months back, and other two patients presented with recent SAH (at third and seventh days). From the recent evidence on the use of FD in ruptured aneurysms, it has been observed that large aneurysms and posterior circulation aneurysms have more risk of associated complications. ${ }^{5}$ In this small series, all aneurysms were present in anterior circulation, and $72.7 \%$ of these were greater than $7 \mathrm{~mm}$.

The goals of anesthesia for FD placement are similar to those required for other intracranial neurointerventional procedures. These include making the patient immobile during procedure, maintaining stable blood pressure, managing anticoagulation, managing intraoperative complications, early and prompt recovery, safe transport of patients, and following radiation safety rules. The blood pressure goals have to be individualized based on patient's baseline value. In this series, there were few episodes of transient hypotension and hypertension in some of the patients, which possibly did not require any active management as no data on drug use were available. In cases of intraprocedural thrombosis, a balance has to be maintained by keeping the blood pressure in high normal range. Low blood pressures are avoided to maintain good cerebral perfusion. At the same time, a very high blood pressure has to be avoided to prevent any hemorrhagic event as these patients receive heparin intraoperatively and are on antiplatelet agents also.

In our institute for therapeutic neurointerventional procedures, we usually administer general anesthesia (GA). As it is a relatively newer technique mostly used for difficult-to-treat aneurysms, GA has been commonly used for carrying out these procedures in various studies. ${ }^{6,7}$ On the other hand, monitored anesthesia care allows for prompt detection of intraoperative complications that otherwise can be appreciated only after extubation. In a retrospective matched cohort study, authors found that placement of an FD can be safely performed under conscious sedation and is associated with reduced procedure length. The rates of procedural complications were comparable between both groups, and no complication attributable to GA was recorded. However, for conscious sedation, the patient should be cooperative; intervention should not be too complex; and an experienced operator should perform the intervention. ${ }^{8}$ In another study, monitored anesthesia care was used for daycare treatment of cerebral aneurysms with the same-day discharge. ${ }^{9}$ However, for this, patients should be carefully selected, and they should fulfill the criteria for safe discharge. In this series, all patients received GA for carrying out these procedures. Propofol was the most commonly used induction agent, and sevoflurane in oxygen/nitrous mixture (40:60) was used as the maintenance agent in all except two patients who received propofol infusion.

In addition to standard ASA (American Society of Anesthesiologists) monitoring, arterial blood pressure monitoring was performed in all patients to titrate it closely. Peripheral intravenous access usually suffices in all these patients, and central line is generally not required. Bispectral index is useful for titrating the anesthetic depth in these patients and may help in early recovery. Near-infrared spectroscopy provides information about cerebral oxygenation and is a predictive marker of critical perfusion changes. ${ }^{10}$

Patients received dual-antiplatelet agents such as aspirin and clopidogrel 5 days before procedure, and these are continued thereafter typically for 6 months similar to common practice. ${ }^{11}$ After a period of 6 months, clopidogrel is stopped and aspirin is continued for rest of life. In addition, where priming was not possible, aspirin and clopidogrel $300 \mathrm{mg}$ each were given 4 hours before procedure. However, the practice varies regarding the optimal dose, agent, and timing of antiplatelet agent used. The use of antiplatelets in acute SAH carries risk of aneurysmal rebleeding. In such cases, single dose of aspirin and loading dose of GpIIb/IIla inhibitor may be administered or a dose of aspirin before procedure followed by clopidogrel at end of procedure. ${ }^{12,13}$ At our institute, patients with recent-onset SAH received only postprocedural antiplatelets (aspirin $75 \mathrm{mg}$ OD, clopidogrel $150 \mathrm{mg}$ ). We did not perform aspirin and clopidogrel response testing in any patient.

The periprocedural complications may vary from thromboembolic or ischemic events, side branch occlusions, parent artery injury, and/or rupture and malposition or migration of FDs. ${ }^{14}$ These are associated with significant morbidity and should be recognized and treated promptly. There were no intraoperative complications except in one patient who developed FD thrombosis. As these acute thrombi are platelet-rich, antiplatelet agents such as abciximab, tirofiban and eptifibatide are most effective for clot disruption. Blood pressure may be augmented to tide over the period of acute thrombus formation. In this case, it resolved promptly, and the patient was extubated post procedure. The neurointervention suite is usually cold and 4 out of 22 patients developed intraoperative hypothermia $\left(34^{\circ} \mathrm{C}\right)$. These patients had inadequate reversal and were mechanically ventilated postoperatively. One patient developed a large parietal hematoma post procedure and succumbed to death on postoperative 
day 2. Blood pressure should be optimized such as to prevent aneurysmal bleed, prevent aggravation of any brain edema, and to maintain a good flow across the parent artery. However, this needs to be studied further, and optimum goals need to be established.

The long-term safety and efficacy of FD is yet to be studied. A trial aimed to study the effect of flow diversion versus traditional coil-based endovascular therapy comparing the standard treatment with FD placement has been terminated because of the rarity of disease and difficulty in enrollment. ${ }^{15}$ In a meta-analysis, the authors concluded that the risk of procedure-related morbidity and mortality cannot be neglected in FD placement. Patients with posterior circulation aneurysms are at higher risk of ischemic stroke, particularly perforator infarction. These findings should be considered when considering the best therapeutic option for intracranial aneurysms. ${ }^{4}$ We observed that one patient developed FD-related thrombosis of internal carotid artery, which was promptly recognized and treated during procedure, which resulted in an uneventful recovery. However, two patients in this case series developed postprocedural mild motor weakness that subsequently improved over the next few months. After the procedure, there may occur peri-aneurysmal vasogenic edema in the brain parenchyma, more likely if aneurysm is large, partially thrombosed, or close to the brain parenchyma. ${ }^{16,17}$ The proximity of the treated aneurysm to the brain parenchyma probably causes inflammation, blood-brain barrier disruption, and edema formation. This may lead to aggravation of headache or clinical deterioration. Few may prefer to administer dexamethasone for 1 to 2 weeks to cover high-risk period; however, there are no clear recommendations about it. ${ }^{18}$

In a randomized trial comparing flow diversion and best standard treatment-the FIAT trial, the authors had to stop the trial due to safety concerns. The primary hypothesis is that flow diversion can be performed with an "acceptable" immediate complication rate, defined as less than $15 \%$ morbidity and mortality; however, they found out that $16 \%$ patients had either died or became dependent after FD placement. ${ }^{19}$ In this study, progressive mass effect, periprocedural arterial rupture, carotid thrombosis due to migration of FD, and delayed rupture were the predominant causes of poor clinical outcome. Hence, the authors concluded that flow diversion was not safe and effective as hypothesized. However, in this series, except for one patient, others had a good functional outcome. Delayed aneurysm rupture and delayed intraparenchymal hemorrhages (DIPHs) are often fatal complications of FD placement for intracranial aneurysms. In one such study, the delayed ruptures accounted for $76.6 \%$ within 1 month and the associated prognosis was poor. ${ }^{20}$ In our experience, only one patient had a fatal hemorrhagic complication that occurred immediately in the postprocedure period. However, we did not notice any DIPH. Thus, the rate of complication in our series is only $4.5 \%$ as compared with 15 to $18 \%$ found in the literature. The neurological outcome at discharge and at 6 months was good (GOS 4/5) in 21 out of 22 patients (95.4\%).

\section{Conclusions}

In this clinical report, we found that FD placement is an attractive, innovative, and safe way of treating intracranial aneurysm with few rates of complication. The neurological outcome was good in all patients who were followed at 6 months. Periprocedural anesthetic and intensive care management of such patients requires updated knowledge regarding the dynamics of the FS, anesthetic goals, and associated early and delayed risks associated with them.

Conflict of Interest

None declared.

\section{References}

1 Kallmes DF, Ding YH, Dai D, Kadirvel R, Lewis DA, Cloft HJ. A new endoluminal, flow-disrupting device for treatment of saccular aneurysms. Stroke 2007;38(8):2346-2352

2 Kallmes DF, Ding YH, Dai D, Kadirvel R, Lewis DA, Cloft HJ. A second-generation, endoluminal, flow-disrupting device for treatment of saccular aneurysms. Am J Neuroradiol 2009;30(6):1153-1158

3 Arrese I, Sarabia R, Pintado R, Delgado-Rodriguez M. Flow-diverter devices for intracranial aneurysms: systematic review and meta-analysis. Neurosurgery 2013;73 (2):193-199,discussion199-200

4 Brinjikji W, Murad MH, Lanzino G, Cloft HJ, Kallmes DF. Endovascular treatment of intracranial aneurysms with flow diverters: a meta-analysis. Stroke 2013;44(2):442-447

5 Cagnazzo F, di Carlo DT, Cappucci M, Lefevre PH, Costalat V, Perrini P. Acutely ruptured intracranial aneurysms treated with flow-diverter stents: a systematic review and metaanalysis. Am J Neuroradiol 2018;39(9):1669-1675

6 Bhogal P, Martinez Moreno R, Ganslandt O, Bäzner H, Henkes $\mathrm{H}$, Perez MA. Use of flow diverters in the treatment of unruptured saccular aneurysms of the anterior cerebral artery. J Neurointerv Surg 2017;9(3):283-289

7 Briganti F, Leone G, Cirillo L, de Divitiis O, Solari D, Cappabianca P. Postprocedural, midterm, and long-term results of cerebral aneurysms treated with flow-diverter devices: 7-year experience at a single center. Neurosurg Focus 2017;42(6):E3

8 Griessenauer CJ, Shallwani H, Adeeb N, et al. Conscious sedation versus general anesthesia for the treatment of cerebral aneurysms with flow diversion: a matched cohort study. World Neurosurg 2017;102:1-5

9 Zanaty M, Daou B, Chalouhi N, et al. Same-day discharge after treatment with the pipeline embolization device using monitored anesthesia care. World Neurosurg 2016;96:31-35

10 Rummel C, Zubler C, Schroth G, et al. Monitoring cerebral oxygenation during balloon occlusion with multichannel NIRS. J Cereb Blood Flow Metab 2014;34(2):347-356

11 Rajah G, Narayanan S, Rangel-Castilla L. Update on flow diverters for the endovascular management of cerebral aneurysms. Neurosurg Focus 2017;42(6):E2

12 Chiu AH, Ramesh R, Wenderoth J, Davies M, Cheung A. Use of aspirin as sole oral antiplatelet therapy in acute flow diversion for ruptured dissecting aneurysms. J Neurointerv Surg 2017;9(5):e18

13 Girdhar G, Li J, Kostousov L, Wainwright J, Chandler WL. In-vitro thrombogenicity assessment of flow diversion and aneurysm bridging devices. J Thromb Thrombolysis 2015;40(4):437-443

14 Al-Mufti F, Cohen ER, Amuluru K, et al. Bailout strategies and complications associated with the use of flow-diverting 
stents for treating intracranial aneurysms. Intervent Neurol 2019;8:38-54

15 Turk AS III, Martin RH, Fiorella D, Mocco J, Siddiqui A, Bonafe A. Flow diversion versus traditional endovascular coiling therapy: design of the prospective LARGE aneurysm randomized trial. Am J Neuroradiol 2014;35(7):1341-1345

16 Hammoud D, Gailloud P, Olivi A, Murphy KJ. Acute vasogenic edema induced by thrombosis of a giant intracranial aneurys a cause of pseudostroke after therapeutic occlusion of the parent vessel. Am J Neuroradiol 2003;24(6):1237-1239

17 Berge J, Tourdias T, Moreau J-F, Barreau X, Dousset V. Perianeurysmal brain inflammation after flow-diversion treatment. Am J Neuroradiol 2011;32(10):1930-1934
18 Saatci I, Yavuz K, Ozer C, Geyik S, Cekirge HS. Treatment of intracranial aneurysms using the pipeline flow-diverter embolization device: a single-center experience with long-term follow-up results. Am J Neuroradiol 2012;33(8):1436-1446

19 Raymond J, Gentric JC, Darsaut TE, et al. Flow diversion in the treatment of aneurysms: a randomized care trial and registry. J Neurosurg 2017;127(3):454-462

20 Rouchaud A, Brinjikji W, Lanzino G, Cloft HJ, Kadirvel R, Kallmes DF. Delayed hemorrhagic complications after flow diversion for intracranial aneurysms: a literature overview. Neuroradiology 2016;58(2):171-177

\section{Anesthetic Management of a Patient with Pacemaker Undergoing Clipping of Intracranial Aneurysm}

Summit D. Bloria ${ }^{1}$ Shiv Lal Soni ${ }^{1} \quad$ Ketan Kataria ${ }^{1} \quad$ Pallavi Bloria ${ }^{2}$

\author{
Address for correspondence Summit D. Bloria, MD, Department of \\ Anesthesia, Postgraduate Institute of Medical Education and Research, \\ c/o 3245 Sector 15D, Chandigarh, 160015, Punjab, India \\ (e-mail: summitbloria13@gmail.com).
}
Abstract
Keywords
- aneurysm
- cerebral aneurysm clipping
- pacemaker

Pacemaker devices have revolutionized the lives of patients with cardiac arrhythmias and have become increasingly common. Anesthetic management of patients with cardiac pacemakers provides special challenges. We describe our experience of a patient having implanted permanent pacemaker posted for clipping of ruptured intracranial aneurysm.

\section{Introduction}

Anesthetic management of patients with implanted pacemaker requires a thorough knowledge of the indication for pacemaker placement, present mode of pacemaker, and extent of dependency of the patient on pacemaker. In patients with pacemakers who are undergoing neurosurgery, the additional considerations include the proximity of operative site to the pacemaker, prolonged duration of surgery, potential for major amount of blood loss, cardiac insults
Published online

April 30, 2020
Dol https://doi.org/

$10.1055 / \mathrm{s}-0039-1685248$

ISSN 2348-0548.
(C2020. Indian Society of Neuroanaesthesiology and Critical Care. This is an open access article published by Thieme under the terms of the Creative Commons Attribution-NonDerivative-NonCommercial-License, permitting copying and reproduction so long as the original work is given appropriate credit. Contents may not be used for commercial purposes, or adapted, remixed, transformed or built upon. (https://creativecommons.org/licenses/by-nc-nd/4.0/).

Thieme Medical and Scientific Publishers Pvt. Ltd. A-12, 2nd Floor, Sector 2, Noida-201301 UP, India 